\title{
Climate Warming Can Accelerate Carbon Fluxes without Changing Soil Carbon Stocks
}

\section{OPEN ACCESS}

Edited by

Samuel Abiven

University of Zurich, Switzerland

Reviewed by:

Carlos A. Sierra

Max Planck Institute for

Biogeochemistry, Germany

Sylvie Quideau,

University of Alberta, Canada

*Correspondence:

Susan E. Ziegler

sziegler@mun.ca

${ }^{\dagger}$ Present Address:

Michael Philben,

Oak Ridge National Laboratory,

Environmental Science Division, Oak

Ridge, TN, USA

Jerome Laganière,

Laurentian Forestry Centre, Natural

Resources Canada, Canadian Forest Service, Quebec City, QC, Canada

Specialty section This article was submitted to Biogeoscience, a section of the journal

Frontiers in Earth Science

Received: 10 November 2016

Accepted: 11 January 2017

Published: 03 February 2017

Citation:

Ziegler SE, Benner R, Billings SA, Edwards KA, Philben M, Zhu X and Laganière J (2017) Climate Warming Can Accelerate Carbon Fluxes without Changing Soil Carbon Stocks. Front. Earth Sci. 5:2. doi: 10.3389/feart.2017.00002

\author{
Susan E. Ziegler ${ }^{1 *}$, Ronald Benner ${ }^{2}$, Sharon A. Billings ${ }^{3}$, Kate A. Edwards ${ }^{4}$, \\ Michael Philben ${ }^{1+}$, Xinbiao Zhu ${ }^{4}$ and Jerome Laganière ${ }^{1 \dagger}$
}

${ }^{1}$ Department of Earth Sciences, Memorial University of Newfoundland, St. John's, NL, Canada, ${ }^{2}$ Department of Biological Sciences and Marine Science Program, University of South Carolina, Columbia, SC, USA, ${ }^{3}$ Department of Ecology and Evolutionary Biology, Kansas Biological Survey, University of Kansas, Lawrence, KS, USA, ${ }^{4}$ Atlantic Forestry Centre, Natural Resources Canada, Canadian Forest Service, Corner Brook, NL, Canada

Climate warming enhances multiple ecosystem C fluxes, but the net impact of changing C fluxes on soil organic carbon (SOC) stocks over decadal to centennial time scales remains unclear. We investigated the effects of climate on $\mathrm{C}$ fluxes and soil $\mathrm{C}$ stocks using space-for-time substitution along a boreal forest climate gradient encompassing spatially replicated sites at each of three latitudes. All regions had similar SOC concentrations and stocks (5.6 to $6.7 \mathrm{~kg} \mathrm{C} \mathrm{m}^{-2}$ ). The three lowest latitude forests exhibited the highest productivity across the transect, with tree biomass:age ratios and litterfall rates 300 and $125 \%$ higher than those in the highest latitude forests, respectively. Likewise, higher soil respiration rates ( $55 \%)$ and dissolved organic C fluxes ( $300 \%)$ were observed in the lowest latitude forests compared to those in the highest latitude forests. The mid-latitude forests exhibited intermediate values for these indices and fluxes. The mean radiocarbon content $\left(\Delta^{14} \mathrm{C}\right)$ of mineral-associated SOC $(+9.6 \%)$ was highest in the lowest latitude forests, indicating a more rapid turnover of soil $\mathrm{C}$ compared to the mid- and highest latitude soils $\left(\Delta^{14} \mathrm{C}\right.$ of -35 and $-30 \%$, respectively). Indicators of the extent of soil organic matter decomposition, including $\mathrm{C}: \mathrm{N}, \delta^{13} \mathrm{C}$, and amino acid and alkyl-C:O-alkyl-C indices, revealed highly decomposed material across all regions. These data indicate that the lowest latitude forests experience accelerated $\mathrm{C}$ fluxes that maintain relatively young but highly decomposed SOC. Collectively, these observations of within-biome soil $\mathrm{C}$ responses to climate demonstrate that the enhanced rates of SOC loss that typically occur with warming can be balanced on decadal to centennial time scales by enhanced rates of $\mathrm{C}$ inputs.

Keywords: soil carbon, climate change, boreal forests, organic matter biogeochemistry, ecosystem carbon fluxes

\section{INTRODUCTION}

Ecosystem C fluxes typically respond positively to climate warming (Rustad et al., 2001; Hobbie and Chapin, 2008; Hopkins et al., 2012; Natali et al., 2012), but the net impact of changing $\mathrm{C}$ fluxes on soil organic carbon (SOC) stocks over decadal to centennial time scales remains unclear. This uncertainty is in large part responsible for the lack of consensus among Earth system models (ESMs) (Arora et al., 2013; Friedlingstein et al., 2014), which currently struggle to project soil C turnover and stocks accurately (Todd-Brown et al., 2013). Much of 
the existing knowledge of the net response of SOC to climate is derived from manipulative studies (Hobbie and Chapin, 2008; Sistla et al., 2014), providing insights about responses on relatively short (e.g., days to years) timescales. The few studies that examine longer-term climate manipulations of individual ecosystems (e.g., Melillo et al., 2011; Sistla et al., 2014) often focus on a single driving variable, which is useful for constraining the role of specific climate factors. However, this approach can limit inferences at the ecosystem scale. For example, heating part of the ecosystem limits assessments of independent and interactive effects of multiple drivers of ecosystem processes (Rustad et al., 2001). As a result, current understanding of interactive effects and resultant ecosystem C fluxes in response to climate change is insufficient to predict SOC feedbacks to climate on the multi-decadal timescales most relevant to contemporary, anthropogenic climate change. Indeed, ESMs sometimes lack consensus even on the direction of change (Qian et al., 2010; Arora et al., 2013; Friedlingstein et al., 2014).

In contrast to manipulative studies, global- and continentalscale observations (Post et al., 1982; Jobbágy and Jackson, 2000; Bond-Lamberty and Thomson, 2010; Doetterl et al., 2015) capture the combined influences of biology, geochemistry, temperature and precipitation patterns on SOC dynamics across longer (centuries to millennia) timescales, and indicate that climate (Amundson, 2001) and its impact on geochemical features of soil can alter SOC stocks (Torn et al., 1997; Doetterl et al., 2015). For example, with increasing latitude from equatorial to polar regions, the proportion of SOC in surface horizons increases, similar to patterns of increasing precipitation and clay content and decreasing temperature (Post et al., 1982). Also correlating with this latitudinal change, soil respiration decreases (Bond-Lamberty and Thomson, 2010) and, more broadly, SOC turnover in organic horizons decreases (Jobbágy and Jackson, 2000) toward the poles. In relatively warm climates ecosystem $\mathrm{C}$ losses generally increase to a greater degree than net primary productivity (Schlesinger and Bernhardt, 2013), suggesting the potential for net soil C losses (De Deyn et al., 2008), which is consistent with observations of surface soils across biomes.

Inferences derived from comparisons among biomes, however, do not necessarily apply to within-biome SOC processes (Rustad et al., 2001), and it remains unclear how C cycling within individual biomes will respond to climate change on decadal to centennial timescales, prior to a shift in biome identity. Studies that employ natural environmental gradients can provide compelling evidence of the role of climate factors in regulating soil $\mathrm{C}$ fluxes, composition and stocks within biomes (Kane et al., 2005; Bahn et al., 2008; Zimmermann et al., 2009; Norris et al., 2010), but very few integrate multiple C fluxes into a unified study and even fewer include measures of soil C turnover (but see Giardina et al., 2014). Implementing such studies is problematic for multiple reasons. They entail expansive spatial and temporal scales of inquiry, requiring quantification of multiple SOC inputs, transformations, and losses across multiple soil profiles. They typically also reflect inputs to soil profiles that exhibit distinct characteristics, and as such cannot reveal the impact of climate change prior to climate-induced vegetation shifts (Sjogersten et al., 2003). Soil moisture, an important driver of SOC responses to temperature (Post et al., 1982; Trumbore and Harden, 1997; Jobbágy and Jackson, 2000; Preston et al., 2006), also can co-vary across temperature or climate gradients, complicating the interpretation of observed patterns across such gradients (Kane et al., 2005; Hilli et al., 2008; Norris et al., 2010).

We addressed many of these challenges by determining the sources, transformations and fates of SOC along a spatially replicated, mesic boreal forest climate transect to project the impact of contemporary, anthropogenic climate change (i.e., in the coming century) on SOC stocks. The study sites are similar in forest composition, successional stage, and soil moisture, but they differ in mean annual temperature (MAT; 0 to $5.2^{\circ} \mathrm{C}$ ) and precipitation (MAP; 1074 to $1505 \mathrm{~mm}$. Both MAT and MAP increase with decreasing latitude, analogous to predicted climate change for much of this biome within the next century (Stocker et al., 2013), and resulting in similar soil moisture regimes along the transect Table 1. The focus on these mesic forests, similar in most respects except for temperature and precipitation, is a key attribute shared by few other studies and thus differs from most climate transect studies, which typically reflect the net result of changing vegetation, soil type, and moisture limitations. Furthermore, the few studies where both MAT and MAP increase such that soil moisture regime is consistent focus on SOC turnover or chemical composition (Fissore et al., 2009). Very few combine these measures with quantified ecosystem C fluxes (but see Giardina et al., 2014). By addressing the question of how SOC stocks and fluxes vary along this constrained latitudinal gradient, we are able to assess the likely response of soil $\mathrm{C}$ in a region where both soil microbial activity and tree productivity (Charney et al., 2016) are not likely to be limited by available water in a warmer future. By combining measures of soil $\mathrm{C}$ turnover and its chemistry with quantified ecosystem $\mathrm{C}$ fluxes, we provide independent lines of evidence for some of the direct impacts of projected temperature and precipitation changes on soil C.

\section{MATERIALS AND METHODS}

\section{Description of Study Sites and Sampling}

The forest sites in this study are part of the Newfoundland and Labrador Boreal Ecosystem Latitudinal Transect (NL-BELT), a climosequence consisting of mature stands dominated by balsam fir (Abies balsamifera (L.) Mill.) underlain by humo-ferric podzol soils. According to growth yield curves established for each region, the ages of dominant trees at each site were all within $\sim 10$ years of the age at which site maturity is reached. All sites represent closed-canopy forests at a similar, mature stage of maximum net primary productivity. This is an important attribute for comparing ecosystem $\mathrm{C}$ fluxes in isolation of stand ontogeny (Kane et al., 2005). Harvesting and insect outbreaks are the major mechanisms of stand replacement in each region, with no evidence of fire in any site. The regions investigated here span a $5.2^{\circ} \mathrm{C}$ gradient in mean annual temperature and a range of 1074 to $1505 \mathrm{~mm}$ in mean annual precipitation (Table 1).

Three sites were located in each of the three major study regions, Grand Codroy (GC), Salmon River (SR), Eagle River (ER) (Figure 1). At each site, triplicate sampling plots were 
TABLE 1 | Study region and site characteristics.

\begin{tabular}{|c|c|c|c|c|c|c|c|c|c|c|c|}
\hline \multirow{2}{*}{$\begin{array}{l}\text { Region } \\
\text { Site }\end{array}$} & \multirow{2}{*}{$\begin{array}{c}\text { Elev } \\
(m)\end{array}$} & \multirow{2}{*}{$\begin{array}{c}\text { Tree age } \\
\text { (y) }\end{array}$} & \multirow[t]{2}{*}{ Geology of till } & \multicolumn{2}{|c|}{ O Horiz. $\Delta{ }^{14} \mathrm{C}(\%)$} & \multicolumn{2}{|c|}{ Soil moisture VWC } & \multicolumn{4}{|c|}{ Mineral soil characteristics } \\
\hline & & & & $\mathbf{F}$ & $\mathbf{H}$ & LFH & B & C:Mpy & $\%$ silt & \%clay & $\Delta^{14} \mathrm{C}$ \\
\hline ER & & $119(14)$ & & 176 & 136 & $0.23(0.11)$ & $0.32(0.02)$ & $9.1(1.5)$ & $34(2.3)$ & $4.0(0.3)$ & $-30.0(17.9)$ \\
\hline 1 & 145 & $133(33)$ & G,Gd,D & & & 0.22 & 0.31 & 9.6 & $32(0.8)$ & $4.4(1.4)$ & -22.6 \\
\hline 2 & 170 & $118(50)$ & $\mathrm{I}_{F, Q, M} ; \mathrm{Gd}$ & & & 0.33 & 0.31 & 7.5 & $32(0.3)$ & $3.9(1.1)$ & -16.9 \\
\hline 3 & 136 & $105(38)$ & $G, D, D G$ & & & 0.12 & 0.35 & 10.3 & $36(4.0)$ & $3.8(1.7)$ & -50.4 \\
\hline SR & & $97(29)$ & & 151 & 119 & $0.28(0.12)$ & $0.29(0.14)$ & $9.9(2.9)$ & $38(8.0)$ & $16(7.9)$ & $-34.7(35.0)$ \\
\hline 1 & 31 & $66(22)$ & L,S,Sh & & & 0.20 & 0.24 & 13.2 & $46(7.9)$ & $25(12)$ & -62.2 \\
\hline 2 & 16 & $100(6)$ & $\mathrm{G}, \mathrm{S}$ & & & 0.23 & 0.18 & 7.8 & $29(11)$ & $9.0(2.9)$ & 4.73 \\
\hline 3 & 38 & $124(47)$ & $L, S, S h$ & & & 0.42 & 0.44 & 8.5 & $41(12)$ & 15 (5.2) & -46.6 \\
\hline GC & & $47(6)$ & & 155 & 140 & $0.30(0.05)$ & $0.37(0.09)$ & $9.1(1.5)$ & 37 (11) & $6.3(1.7)$ & $10.9(7.5)$ \\
\hline 1 & 100 & $50(5)$ & S,TS & & & 0.36 & 0.39 & 9.6 & $47(2.8)$ & $7.2(1.3)$ & 17.6 \\
\hline 2 & 165 & $40(8)$ & $\mathrm{S}, \mathrm{Go}, \mathrm{G}$ & & & 0.29 & 0.28 & 7.5 & $26(11)$ & $4.3(2.6)$ & 2.73 \\
\hline 3 & 215 & $52(9)$ & $\mathrm{S}, \mathrm{Go}, \mathrm{G}$ & & & 0.26 & 0.45 & 10.3 & $37(2.1)$ & $7.4(2.5)$ & 12.4 \\
\hline
\end{tabular}

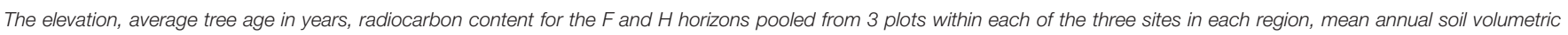

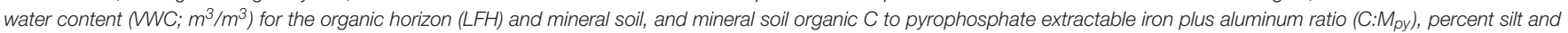

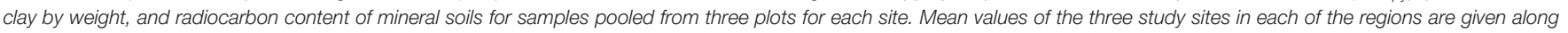

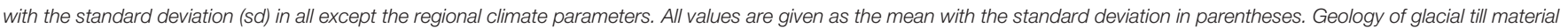

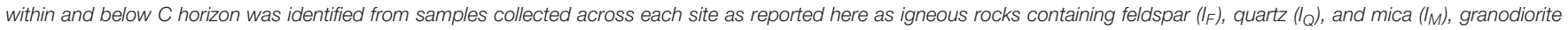
$(G d)$, granite $(G)$, diorite $(D)$, diorite gneiss $(D G)$, gabbro $(G o)$, sandstone $(S)$, talc schist (TS), limestone (L), and shale (Sh).

established. Soil samples were pooled to establish three composite samples for each of the nine study sites (Figure 1). An area of $20 \times 20 \mathrm{~cm}$ was removed to obtain the organic layer (L, $\mathrm{F}$ and $\mathrm{H}$ horizons). The top $10 \mathrm{~cm}$ of the mineral $\mathrm{B}$ horizon was collected using a metal corer $\left(5.1 \mathrm{~cm}\right.$ diameter). The $\mathrm{A}_{e}$ horizon was discontinuous across all sites and was too thin to sample in $\sim 60 \%$ of the plots and was not found at all in $\sim 20 \%$ of the plots. The organic layers were separated into three $\mathrm{O}$ horizons. The $\mathrm{O}$ horizon samples and mineral soil samples were dried at $50^{\circ} \mathrm{C}$ and ground for analysis (total of 108 samples). The average tree biomass and age was determined for each site using the Canadian Forest Service National Forest Inventory (NFI) Protocol (Beaudoin et al., 2014). Ring counting of cores taken at breast height was used to obtain the average age of the trees in each stand. Each core captured the bole's center, with an average of 23 trees cored at each of the 9 sites. Total tree biomass was determined from the measurement of all trees $\geq 9.0$ $\mathrm{cm}$ dbh within the $400 \mathrm{~m}^{2}$ circular NFI plot in each site using the diameter breast height ( $\mathrm{dbh} ; 1.3 \mathrm{~m})$. Tree biomass contributed from those trees $<9 \mathrm{~cm}$ in diameter represented $<1$ to $6 \%$ of the total biomass across all sites.

\section{Litter Soil Input Fluxes}

Litterfall was collected over a four-year period from June 2011 to June 2015 using nine ( 3 per plot), $0.34 \mathrm{~m}^{2}$ collection traps located throughout each of the nine study sites. Litterfall was collected at the end of summer, in late fall, and in early spring of each year and contents were sorted into major component types (green needles, brown needles, cones, bark, lichen, and twig wood $<1 \mathrm{~cm}$ diameter), dried, and weighed. The annual weightedaverage $\% \mathrm{C}$ of each type, with the exception of the twig wood, from the 2011 to 2012 sampling was determined and applied to all collection times to establish total annual litterfall $\mathrm{C}$ for each of the 4 years. The annual weighted $\% \mathrm{C}$ of each input type was determined by creating pooled samples of each type by plot, based on the seasonally-weighted contributions of each to the annual total litterfall. These pooled samples were then analyzed for $\%$ C. Twigs $<1 \mathrm{~cm}$ in diameter were added to this total annual input by assuming a $50 \% \mathrm{C}$ content and using the annual input rates of twigs in each plot.

\section{Dissolved Organic Carbon Fluxes}

The flux of dissolved organic carbon (DOC) was determined using passive pan lysimeters installed below the organic horizon in all regions. Nine lysimeters were installed (3 per plot) in each of the ER-1, SR-1 and GC-1 sites during summer 2011. The lysimeters have a collection area of $0.064 \mathrm{~m}^{2}$. Water samples were collected at least 3 times per year from summer 2011 through summer 2014 and analyzed for DOC content. The pan (zero-tension) lysimeters each consist of a $48 \times 25.5 \times 15$ $\mathrm{cm}(1 \times \mathrm{w} \times \mathrm{d})$ container overlain with a hard plastic mesh grate installed directly beneath the organic soil horizons, and connected by tubing to a $12 \mathrm{~L}$ holding container buried deeper in the mineral soil. Water samples were pumped from the lysimeters with minimum disturbance to the collection area. Samples were filtered (Whatman GF/F) within 1 day of sampling and filtrates were stored at $4^{\circ} \mathrm{C}$ prior to analysis of dissolved organic carbon (Shimadzu TOC-V). Three out of the nine lysimeters at each site were dosed with mercuric chloride as a fixative to prevent decomposition between collection periods; this treatment did not have a significant effect on the DOC concentrations or fluxes. Therefore, data from all nine lysimeters were used at each site.

\section{Total Soil $\mathrm{CO}_{2}$ Flux Measures}

We measured total soil $\mathrm{CO}_{2}$ loss (root- and microbe-derived), soil temperature and soil moisture content twice a month at 


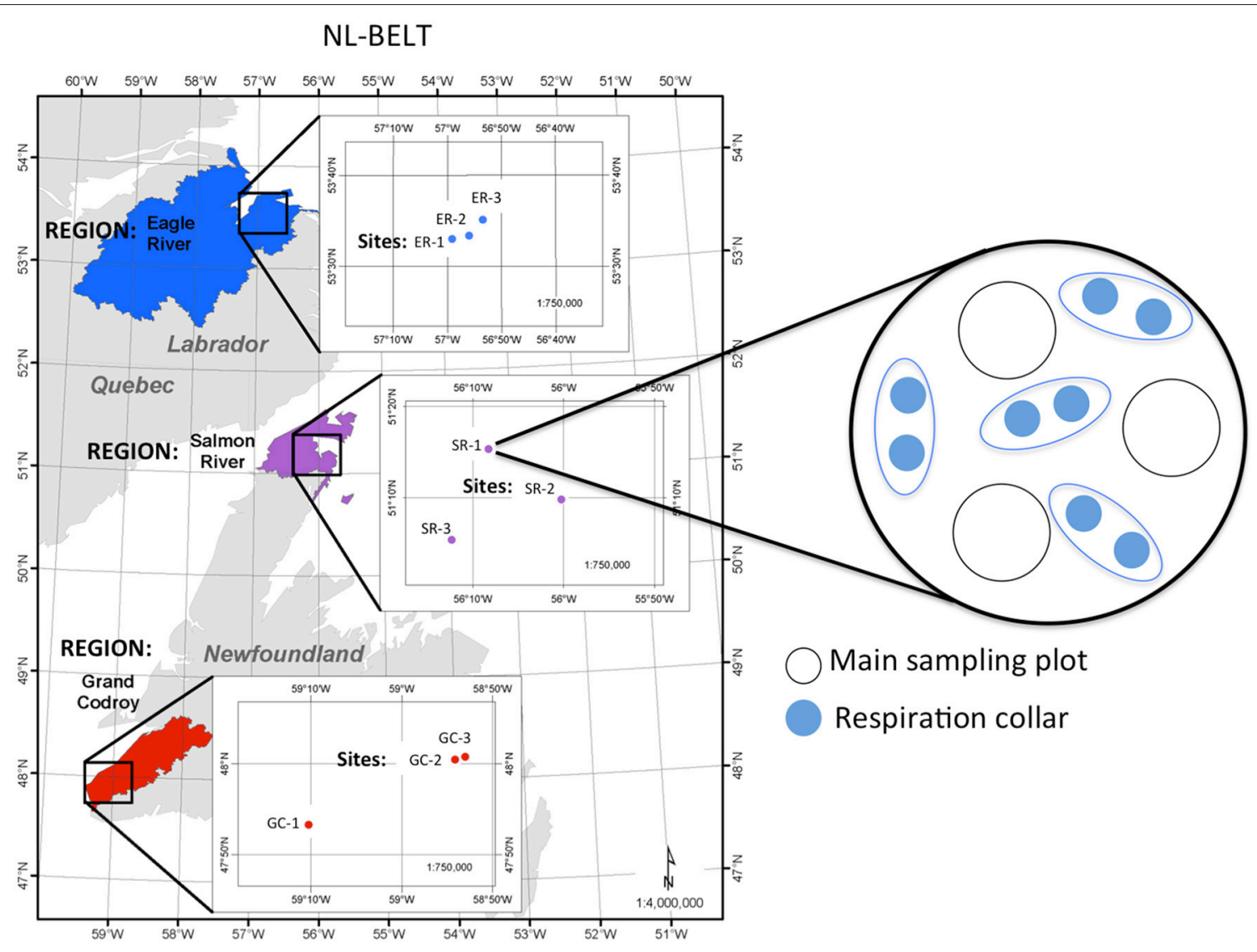

FIGURE 1 | Map of the Newfoundland and Labrador Boreal Ecosystem Latitudinal Transect hydrologic regions, sites and structure of the monitoring and sampling that occurred within each site. The figure includes the Grand Codroy (GC; red); Salmon River (SR; purple); and Eagle River (ER; blue) regions, and the latitudes and longitudes of the three established forest sites in each region. A conceptual drawing of the monitoring and sampling scheme at each of the nine sites is provided. The largest circle depicts the approximate layout of each site, which consists of a homogenous stand roughly $100 \mathrm{~m}$ in diameter. Three $10 \mathrm{~m}$ diameter plots were randomly assigned in each site for soil sampling (triplicate) and litter traps (triplicate). Soil temperature and moisture were continuously monitored at mid depth in the organic horizon and at $5 \mathrm{~cm}$ depth in the mineral soil. Four separate plots were established across each site for measurement of total soil respiration from a pair of collars. Soil temperature and moisture were recorded at sites where soil respiration was measured. Passive pan lysimeters were installed in triplicate within each of the three plots within ER-1, SR-1 and GC-1, and respiration was directly measured at SR-1 and GC-1.

the most accessible sites (SR-1and GC-1) during the snow-free period (May - November) in 2011 and 2012. We installed a pair of PVC collars within each of four plots located within each of the SR-1 and GC-1 sites. These collars (7- $\mathrm{cm}$ section of 10$\mathrm{cm}$ inside diameter) were inserted $4-5 \mathrm{~cm}$ into the forest floor after removing the litter and herbaceous layer. This depth is above the interface of the organic and mineral soil where the majority of roots are found. Total soil $\mathrm{CO}_{2}$ loss was measured using a LI-6400 portable $\mathrm{CO}_{2}$ infrared gas analyzer (IRGA) equipped with a LI-6400-09 soil chamber. Soil temperature and moisture were measured simultaneously using a penetrable soil temperature probe (Licor) and a Campbell Hydro-Sense penetration probe inserted in the soil to $10 \mathrm{~cm}$ in the vicinity (within $\sim 15 \mathrm{~cm}$ ) of each PVC collar. Soil temperature and soil moisture content were also recorded continuously at depths of 5 and $10 \mathrm{~cm}$ at three locations within each of the nine study sites (all three regions) using copper-constantan thermocouples and water content reflectometers attached to data loggers (Campbell Scientific).

Soil temperature was the primary correlate of total soil respiration, while soil moisture did not exert any significant effect in these forest sites (Zhu et al., Personal Communication). We used this knowledge and prior successful use of soil temperature with controlled soil moisture conditions to predict soil $\mathrm{CO}_{2}$ efflux (Lavigne et al., 2003). Combining this information with site specific temperature responses derived from soil incubation results (Podrebarac et al., 2016), we applied soil temperature records to estimate the total soil $\mathrm{CO}_{2}$ flux for snow-free periods at the northern-most ER sites, where frequent $\mathrm{CO}_{2}$ flux measurements were not possible. We also applied this technique to estimate total soil $\mathrm{CO}_{2}$ flux for snow-free periods at the additional uninstrumented SR and GC sites, using site-specific temperature-response models generated from data collected at both SR-1 and GC-1 (see Supplemental Information). 


\section{Soil Carbon Stocks and Organic Matter Chemistry}

The $\mathrm{C}$ and $\mathrm{N}$ concentration and $\mathrm{C}$ and $\mathrm{N}$ stable isotope composition of soils were determined on dried, ground samples. All soil samples for chemical analyses were dried at $50^{\circ} \mathrm{C}$ to a constant weight; subsamples were dried at $105^{\circ} \mathrm{C}$ and used to correct for residual moisture when reporting concentrations relative to dry weight of soil. The $\mathrm{C}$ and $\mathrm{N}$ content and $\delta^{13} \mathrm{C}$ and $\delta^{15} \mathrm{~N}$ of all soil profile samples were analyzed using a Carlo Erba NA1500 Series II Elemental Analyser (Milan, Italy) interfaced to DeltaV+ isotope ratio mass spectrometer (IRMS) via a ConfloIII interface (Thermo, Bremen, Germany) at Memorial University. Larger subsamples of the ground mineral soils were analyzed for $\mathrm{N}$ content and $\delta^{15} \mathrm{~N}$ using $\mathrm{V}_{2} \mathrm{O}_{5}$ and an Elementar Isotope Cube (Germany) interfaced to a Delta Advantage (Thermo, Germany) IRMS via a Conflo III at the G.G Hatch Isotope Laboratory at the University of Ottawa. A comparison of common soil samples for $\mathrm{C}$ content and stable $\mathrm{C}$ isotope composition from this study confirmed consistent results between the two laboratories, enabling combined use of results for the mineral soil samples. We used soil bulk density obtained for all organic horizon and mineral soil samples and to determine soil C stocks.

Samples of each horizon (L, F, H, and B) from each of the three plots were pooled for each site and used for radiocarbon analysis, nuclear magnetic resonance spectroscopy (NMR) and amino acid composition of the mineral horizons. For radiocarbon of the organic horizon, $\mathrm{F}$ and $\mathrm{H}$ horizons were analyzed after they were further pooled for each region. Both the graphitization and radiocarbon analyses were conducted at the University of Georgia Center for Applied Isotope Studies. Radiocarbon content of the mineral soil organic $\mathrm{C}$ was obtained following acid fumigation of ground, dried soil subsamples (Hedges and Stern, 1984) with the cyrogenically purified $\mathrm{CO}_{2}$ generated from the combustion of samples in presence of $\mathrm{CuO}$ and catalytically converted to graphite (Vogel et al., 1984, 1987). Sample ${ }^{14} \mathrm{C} /{ }^{13} \mathrm{C}$ ratios were measured using a CAIS $0.5 \mathrm{MeV}$ accelerator mass spectrometer and compared to the ratio measured from the Oxalic Acid I (NBS SRM 4990) standard. We report both $\Delta^{14} \mathrm{C}$ and inferred mean residence times (MRT) as the mean of three sites' values for each of the three regions. Under steady state conditions, a homogeneous SOC pool's mean residence time, turnover time, and average radiocarbon age are equivalent. Though homogeneity of the soil $\mathrm{C}$ pool is not a valid assumption and thus inferring average radiocarbon age is not appropriate, inferred mean residence times provide a valid, temporal point of reference for our modeling results. All radiocarbon data are corrected for isotope fractionation using the $\delta^{13} \mathrm{C}$ of each subsample.

Due to the high Fe content of the mineral soils in this study, mineral soil samples were processed using a modified version of established methods for soils (Schmidt et al., 1997) to obtain the acid insoluble fraction. A $20 \mathrm{~g}$ sample of each ground mineral sample was weighed directly into $250 \mathrm{~mL}$ polycarbonate centrifuge tubes. Following the addition of $100 \mathrm{~mL}$ of $1 \mathrm{~N} \mathrm{HCl}$ each sample was agitated for $1 \mathrm{~h}$ to remove salts and carbonates. Samples were then centrifuged at $4000 \mathrm{rpm}(\sim 1250 \mathrm{~g})$ for 15 min and the recovered pellet was treated with $100 \mathrm{~mL}$ of a $10 \%$ $(\mathrm{v} / \mathrm{v}) \mathrm{HF}$ solution and shaken for $6 \mathrm{~h}$ at room temperature. Samples were centrifuged again at $4000 \mathrm{rpm}(\sim 1250 \mathrm{~g})$ for 15 min to recover the demineralized residue. Following up to five repetitions of the $\mathrm{HF} / \mathrm{HCl}$ treatment the final residues were then rinsed 3 times with NanoUV water. Final residues were freezedried and homogenized and ground using a mortar and pestle prior to NMR analysis. Using a Bruker AVANCE II $600 \mathrm{MHz}$ equipped with a Bruker $3.2 \mathrm{~mm}$ MAS triple-tuned ${ }^{1} \mathrm{H} /{ }^{19} \mathrm{~F} /{ }^{13} \mathrm{C}$ probe, samples were run at $600.33 \mathrm{MHz}$ for ${ }^{1} \mathrm{H}$ and $150.96 \mathrm{MHz}$ for ${ }^{13} \mathrm{C}$ and spun at $20 \mathrm{kHz}$ at a constant temperature of $25^{\circ} \mathrm{C}$. ${ }^{13} \mathrm{C}$ NMR (CPMAS) experiments had a contact times of $2 \mathrm{~ms}$, the Hartmann-Hahn condition was set at 62.5 and $100 \mathrm{kHz}$ was used for ${ }^{1} \mathrm{H}$ decoupling. The organic horizon samples were analyzed using $4 \mathrm{~K}$ scans while mineral soils required $24 \mathrm{~K}$ scans. ${ }^{13} \mathrm{C}$ chemical shifts were referenced to tetramethylsilane (TMS) with adamantane as an external secondary reference (Harris et al., 2002). Peak fitting was performed using Dmfit (Massiot et al., 2002), with percent areas extracted with the same fitting parameters across all samples.

Samples for total hydrolysable amino acid analysis $(5-10 \mathrm{mg}$ for organic horizon soils, $\sim 25 \mathrm{mg}$ for mineral soils) were added to glass ampules with $1 \mathrm{~mL} 6 \mathrm{~N} \mathrm{HCl}$. Ampules were flame-sealed and heated at $110^{\circ} \mathrm{C}$ for $20 \mathrm{~h}$. Following hydrolysis, ampules were opened and an aliquot was dried under a gentle stream of $\mathrm{N}_{2}$ gas. After dissolving samples in MilliQ water norvaline was added as an internal standard. Amino acids were derivatized using a Phenomenez EZ:Faast kit (Phenomenex, USA) and separated by gas chromatography using a Phenomenex ZB-AAA column and quantified with a flame ionization detector. We assessed the extent of SOM diagenesis by calculating a degradation index based on differences in amino acid composition analogous to degradation indices developed by Dauwe et al. (1999) and Menzel et al. (2015) to interpret the extent of diagenesis of sedimentary organic matter in marine and lacustrine systems. A principle component analysis (PCA) identifying the most significant trends in the full amino acid composition was employed using the mole \% composition of each of the 14 amino acids analyzed in the pooled litter samples and in the L, F, H, and B horizons in the soil profiles (see Supplementary Information for details).

\section{Mineral Soil Size Fractions and Metal Content}

The proportions of silt and clay, and the concentration of non-crystalline and organically complexed $\mathrm{Al}$ and $\mathrm{Fe}$ in the mineral horizon soils were determined for all mineral soil horizons collected at the plot scale $(n=27)$. The silt and clay fractions were separated and evaluated in the $<53 \mu \mathrm{m}$ fraction using dispersion by sonication, wet sieving, flocculation and centrifugation according to Soukup et al. (2008). The noncrystalline $\mathrm{Al}$ and $\mathrm{Fe}$ fraction was extracted using ammonium oxalate $\left(\mathrm{M}_{a o}\right)$, and the $\mathrm{Al}$ and Fe complexed with organic matter $\left(\mathrm{M}_{p y}\right)$ was extracted using sodium pyrophosphate following Courchesne and Turmel (2007). The extracts were analyzed for $\mathrm{Al}$ and Fe on a PerkinElmer Optima 5300 DV inductively coupled plasma optical emission spectrometry (Shelton, CT, USA). The 
ratio of soil $\mathrm{C}$ to the pyrophosphate extractable metal (as $\mathrm{Fe}$ plus $\mathrm{Al}$; C:Mpy) presented here can be indicative of the degree of chelation of soil $\mathrm{C}$ with metal oxides. Complete bonding or complexation of all SOC with $\mathrm{Fe}$ and $\mathrm{Al}$ is likely to happen at $\mathrm{C}: \mathrm{Mpp}<10$ whereas values of C:Mpp > 10 likely indicate that such complexation is not effective (Oades, 1989).

\section{Modeling Soil Radiocarbon}

The SoilR package (version 1.1-25; https://cran.r-project.org/ web/packages/SoilR/index.html; Sierra et al., 2014) was used to estimate the time period over which litter input and SOC mineralization fluxes at GC would need to be sustained at ER to generate mineral horizon SOC $\Delta^{14} \mathrm{C}$ equivalent to that observed at GC. Soil organic $\Delta^{14} \mathrm{C}$ is a result of both ${ }^{14} \mathrm{C}$ inputs to the profile, which accelerated between 1950 and the early 1960s due to atmospheric testing of nuclear weapons, radioactive ${ }^{14} \mathrm{C}$ decay, and losses following SOC decomposition. The half-life of ${ }^{14} \mathrm{C}$ ( $\sim 5730$ years) is long compared to the decadal time scales relevant for SOC cycling, resulting in the mixture of prebomb and post-bomb $\mathrm{C}$ inputs being the key determinants of the observed SOC $\Delta^{14} \mathrm{C}$. For example, $\Delta^{14} \mathrm{C}$ signatures decline by about $6 \%$ in 50 years due to radioactive decay, a small change compared to the atmospheric enrichment of ${ }^{14} \mathrm{C}>500 \%$ in the 1960s. As a result, we used soilR to estimate the time for ER to reach an equivalent level of pre-bomb $\mathrm{C}$ rather than the same absolute $\Delta^{14} \mathrm{C}$ value, due to complications from the rapidly changing atmospheric $\Delta^{14} \mathrm{C}$.

First, we used inverse modeling to constrain the parameters necessary to produce the observed $\Delta^{14} \mathrm{C}$ values at ER and GC. We assumed the mineral horizon $\mathrm{C}$ stocks were in steady state in both regions and that the $\mathrm{C}$ inputs and outputs to the mineral soil were $50 \%$ of the total measured respiration (Buchmann, 2000). A 2-pool model was applied, with the size of the fast and slow pools equivalent to the average SOC pool size in the coarse $(>53 \mu \mathrm{m})$ and fine $(<53 \mu \mathrm{m})$ fractions across all sites in each of the three regions. SOC loss rates for the two pools and the rate of transfer from the fast to the slow pool were determined by modeling from 1950 to 2009 (the last year included in the radiocarbon dataset used in SoilR). Fast- and slow-pool mineralization rates and the rate of transfer between the pools were selected such that the $\mathrm{C}$ stocks remain in steady state and $\Delta^{14} \mathrm{C}$ reaches the observed value in $2009(+10 \%$ for GC, $-30 \%$ for ER; Figure S1). The process was repeated for ER using lower litter inputs and $\mathrm{CO}_{2}$ losses (proportional to the difference in measured respiration rates).

The decay rates determined via inverse modeling were then used to calculate the size of the fast, pre-bomb slow, and postbomb slow $\mathrm{C}$ pools in both regions in 2009. The fast pool was not separated into pre- and post-bomb fractions because the prebomb fast pool is removed over the course of the simulation and does not affect $2009 \Delta^{14} \mathrm{C}$. After determining the size of the pre-bomb $\mathrm{C}$ pool and its loss rate for both regions, the higher GC rate was applied to the ER stock and the model was run forward from 2010 (Figure 4). This model process was used to estimate the time GC fluxes would need to be maintained at ER to reach the GC stock of pre-bomb C. We tested the sensitivity of the model results to our assumption of mineral horizon respiration, the proportion of $\mathrm{C}$ in fastand slow-cycling pools, and the initial $\Delta^{14} \mathrm{C}$ of pre-bomb $\mathrm{C}$ in both regions (Supplemental Information). Of these variables, the initial radiocarbon content of the pre-bomb $\mathrm{C}$ had the largest impact on model results. Therefore, we used a range of initial radiocarbon contents to estimate a range of possible values for the time required for ER SOC stocks to acquire radiocarbon signatures similar to those observed at GC after cycling at GC rates (Figure S2).

\section{Statistical Analyses}

We tested the effect of region on mineral soil radiocarbon, clay content and C: $\mathrm{M}_{\mathrm{pp}}$ ratio, the soil C stocks in the LFH and mineral soil, the total soil $\mathrm{CO}_{2}$ flux for the snow free season, annual soil DOC flux, and litterfall input rates using a one-way ANOVA. Where variances violated the assumption of normalcy, we used the Kruskal-Wallis one-way analysis of variance by ranks. The soil organic matter $\mathrm{C}: \mathrm{N}, \delta^{13} \mathrm{C}$, THAA degradation index, and ratio of alkyl to $\mathrm{O}$-alkyl $\mathrm{C}$ were all tested for the effect of horizon, region and their interaction using a two-way ANOVA. Variances in $\mathrm{C}: \mathrm{N}$ and $\delta^{13} \mathrm{C}$ were not normally distributed when litterfall was included as a horizon in the two way ANOVA but were normally distributed when litterfall was omitted. We present results without the litterfall included in the model. Where region or horizon effects were noted, a post hoc test of all possible pairwise treatment comparisons was accomplished using Tukey's Honest Significant Difference test with a family error rate of 5\%.

The relationship between litter input rates and SOC stocks in the LFH horizon was evaluated using correlation analysis. The factors controlling variation in mineral soil $\mathrm{C}$ concentration (\%C) and stocks were tested using a 3-way ANOVA with litter input, clay concentration (\%), and ammonium extractable $\mathrm{Fe}$ and $\mathrm{Al}\left(\mathrm{M}_{\mathrm{ao}} ; \mathrm{g} \mathrm{kg}\right.$ soil ${ }^{-1}$; a proxy for non-crystalline mineral concentration) and their interactions as independent variables. Given that both litterfall and non-crystalline mineral content had an effect on mineral SOC stocks, we tested for their effects and their interactions on SOC bioreactivity. Here, we define SOC bioreactivity as soil C-normalized cumulative mineral soil respiration ( $\mathrm{mg} \mathrm{C} \mathrm{g} \mathrm{SOC}{ }^{-1}$ ) following 43 and 475 days of incubation at $10^{\circ} \mathrm{C}$ and constant moisture, as reported in Laganière et al. (2015). We also used a two-way ANOVA to assess potential effects of region, C:Mpy ratio and their interaction on SOC bioreactivity. These tests were driven by our anticipation of region being associated with SOM decomposition stage (Laganière et al., 2015) and the utility of C:Mpy ratios as a proxy for the mineral adsorptive capacity of soil (Masiello et al., 2004). Tests were conducted using JMP 8.0 using an $\alpha=0.05$.

\section{RESULTS AND DISCUSSION}

\section{The Balance between Soil C Inputs and Losses with Projected Climate Change}

Carbon fluxes in these boreal forest soils were greatest in the lowest latitude forests, which had the highest MAT and MAP (Figure 2). The relative increases in $\mathrm{C}$ inputs to soils with decreasing latitude were similar in magnitude to the increases in $\mathrm{C}$ removal due to respiration and DOC transport. The ratio of 


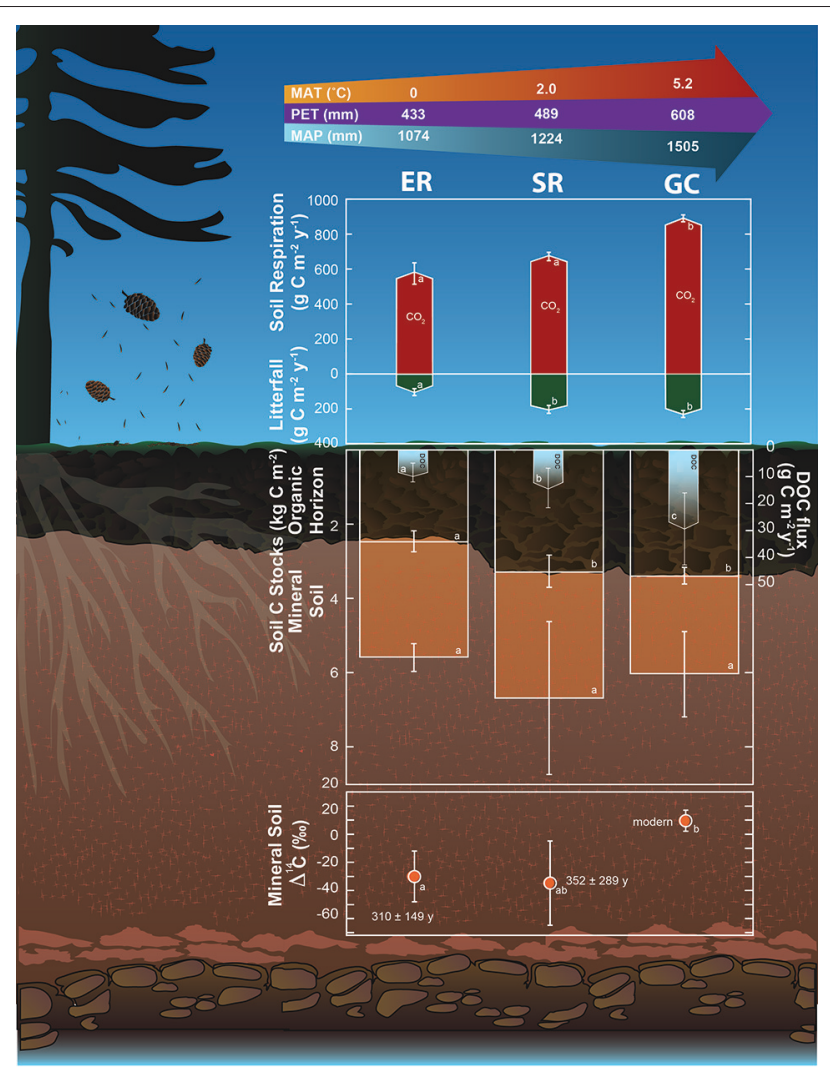

FIGURE 2 | Diagram depicting averaged C stocks and fluxes across three, spatially replicated boreal forests within each of the three regions comprising the Newfoundland and Labrador Boreal

Ecosystem Latitudinal Transect (NL-BELT). The upper most arrow at the top depicts mean annual temperature (MAT), precipitation (MAP), and potential evapotranspiration (PET) for each study region based on the Environment Canada climate normals for 1981-2010 (Government of Canada). Values represent soil organic $\mathrm{C}(\mathrm{SOC})$ stocks in the organic horizon ( $\mathrm{LFH}$ ) and the top $10 \mathrm{~cm}$ of the mineral B horizon (lower stacked bar graphs), litterfall inputs including needles, cones, bark, and twig wood $(<1 \mathrm{~cm}$ diameter) (green arrow bars), total soil $\mathrm{CO}_{2}$ losses (red arrow bars), the transfer flux of dissolved organic carbon (DOC) from the LFH to the surface of the B horizon (blue arrow bars), and the radiocarbon signatures and inferred mean residence times of the soil organic $\mathrm{C}$ in the top $10 \mathrm{~cm}$ of the mineral $\mathrm{B}$ soil (bottom graph). All fluxes are in $\mathrm{g} \mathrm{C} \mathrm{m}^{-2}$ year ${ }^{-1}$; SOC stocks are in $\mathrm{kg} \mathrm{C} \mathrm{m}^{-2}$. Different lower case letters are provided where a significant regional effect was detected within a given $\mathrm{C}$ stock or flux with an $\alpha=0.05$ level. Error bars represent one standard deviation. Error bars emanating from the bottom of the mineral soil $\mathrm{C}$ stock bars represent the cumulative error of the LFH plus mineral soil C stocks.

tree biomass to age, an index of net forest productivity, increased by $\sim 300 \%$ from the coldest to warmest region (Figure 3 ), and litterfall increased by $\sim 125 \%$ (Figure 2). Soils in the warmest region received $129 \mathrm{~g} \mathrm{C} \mathrm{m}^{-2}$ year ${ }^{-1}$ more litterfall than the coolest region. Estimates of fine root inputs to these soils, derived from the average ratio of fine root turnover to needle litterfall inputs in boreal forests ( $\sim 2.2$ Ruess et al., 1996), were $284 \mathrm{~g}$ $\mathrm{C} \mathrm{m}{ }^{-2}$ year $^{-1}$ greater in the warmest region. Soil respiration increased by $\sim 55 \%$ and DOC fluxes to the mineral horizons increased by $300 \%$ with decreasing latitude (Figure 2), suggesting

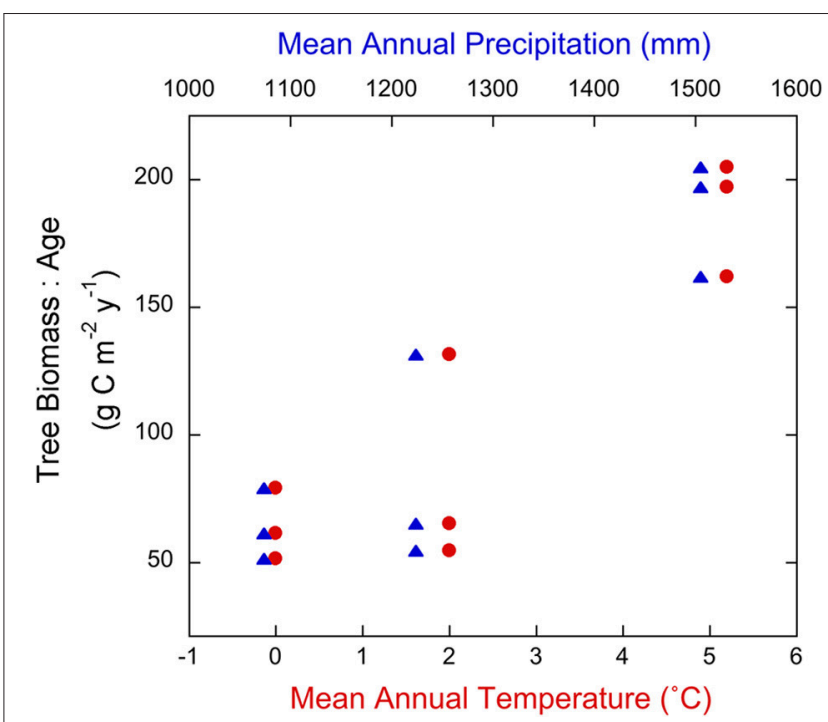

FIGURE 3 | Relationships between a proxy for forest productivity (tree biomass:age) and mean annual temperature (MAT; red circles) and precipitation (MAP; blue triangles) for the sites within each region of the NL-BELT. See text for climate transect details.

a significant increase in the mobilization and subsequent loss of soil $\mathrm{C}$ with increasing temperature and precipitation.

These results highlight important differences in the responses of forest productivity and $\mathrm{C}$ losses to climate across the boreal biome. Not all soil C inputs were directly measured in this study, but consistent $\mathrm{C}$ stocks in organic and mineral soil horizons across the regions provides strong evidence for an approximate balance between $\mathrm{C}$ inputs and losses in these forests. Studies of boreal forests in more continental climates suggest decreases in soil $\mathrm{C}$ stocks with warming along climate gradients (Kane and Vogel, 2009; Norris et al., 2010). However, increases in tree mortality attributed to drought in interior continental boreal forests compared to coastal Canadian forests (Peng et al., 2011) suggest a shift from temperature to precipitation limitation of high latitude forests in continental climate regions. The forests studied here, where MAP can exceed more interiorcontinental sites by up to $1000 \mathrm{~mm}$, receive annual precipitation that exceeds evaporative demand (Figure 2), an important feature impacting the balance of net $\mathrm{C}$ fixation relative to respiration (Dunn et al., 2006). Our results suggest that in regions where forest productivity is predicted to increase under future climate scenarios (Charney et al., 2016; D'Orangeville et al., 2016), soil C inputs can keep pace with the increased losses associated with warming. Experimental warming in temperate forests has revealed initial net losses of $\mathrm{C}$ from soils that were ameliorated by gains in plant productivity in response to warming (Melillo et al., 2011). The present study of intact boreal forest ecosystems that have experienced different climate histories provides direct evidence for the impacts of a naturallyoccurring positive response of productivity to a warmer climate on soil C stocks. Total annual radiation inputs, however, decrease with increasing latitude and represent a climate-independent 
factor that can regulate productivity. For example, the 22-year average solar radiation record from the Surface meteorological and Solar Energy (SSE) web portal (NASA Langley Research Center's Atmospheric Science Data Center) indicates light levels are $\sim 14 \%$ lower in the highest latitude region across the same growing season length as the lowest latitude region of the transect studied here. These features highlight how the extent of any positive productivity response to a warming climate in these ecosystems will depend upon both water and light availability supporting primary production.

Mineral SOC stocks did not differ substantially across regions (Figure 2), and they exhibit generally low soil sorption capacities due to low clay content $(\sim 5 \%)$ and a ratio of SOC to pyrophosphate extractable metal $\left(\mathrm{C}: \mathrm{M}_{\mathrm{py}}\right)$ close to ten (Masiello et al., 2004; Table 1). Variations in mineral soil C stocks observed here (regional standard error of the mean up to $0.54 \mathrm{~kg} \mathrm{C}$ $\mathrm{m}^{-2}$ ) were similar to those reported for surface mineral soils in other boreal forest podzols (Kane et al., 2005; Olsson et al., 2009) where variation can be substantial due in part to spatial variation in soil content. Mean soil content for the top $10 \mathrm{~cm}$ of the mineral soil was $62.6 \pm 5,71.1 \pm 8$, and $79.9 \pm 8 \mathrm{~kg}$ $\mathrm{m}^{-2}$ in the GC, SR and ER regions, respectively. The regional difference in mineral soil content (ANOVA; $p=0.0080$ ) was attributed to a significantly lower soil content in the lowest latitude relative to highest latitude sites $(p=0.0002)$. This indicates that greater soil inputs, and not greater soil content, was likely responsible for the consistent soil C stocks observed across latitude in these forests. Site level variation in soil $\mathrm{C}$ concentration (Figure S3) suggests soil C may also have been associated with site (mineral content and character) or even plot level (litterfall input) characteristics. However, consistent with the general observation of low sorption capacity, the clay concentration exhibited no relationship with mineral SOC (Table S4), while mineral content and inputs exerted a combined influence on mineral SOC. The noncrystalline mineral content (ammonium-oxalate extractable metals; $\mathrm{M}_{\mathrm{AO}}$ ), litterfall input, and their interactions had significant effects on mineral SOC respiration (Table S5) signifying the influence of inputs and metal content on SOC bioavailability in these mineral soils. However, $\mathrm{M}_{\mathrm{AO}}$ was weakly correlated with mineral SOC (Figure S4). This is consistent with the dominant role of inputs in regulating the source and form of mineral SOC, which can be influenced by transport of metals with DOC to the B horizon, particularly in podzols.

To further assess the role of mineral content in regulating SOC stocks in these forest soils, we examined whether the bioreactivity of mineral SOC (Laganière et al., 2015) was related to mineral content, as has been demonstrated in other soil types (Torn et al., 1997; Doetterl et al., 2015). Neither $\mathrm{M}_{\mathrm{AO}}$ or C: $\mathrm{M}_{\text {py }}$ exhibited any relationship with mineral SOC bioreactivity (Table S5; Figure S3), indicating little evidence of a major role for mineral protection in regulating the SOC content of these soils. The absence of geochemical controls on SOC content provides further evidence that climate drives the measured regional differences in $\mathrm{C}$ fluxes. This is congruent with the maintenance of soil $\mathrm{C}$ socks via increased inputs with climate warming.

\section{Mean Residence Time and Extent of Alteration of Soil C Indicate Increased Turnover of SOC with Projected Climate Change}

The radiocarbon content of the SOC provides independent evidence for increased SOC turnover in the lowest latitude forests (Figure 2). Radiocarbon contents were similar among the organic horizon $\mathrm{C}$ pools (Table 1), indicating less pre-bomb $\mathrm{C}$ and thus relatively short mean residence times ( $<30$ year). Such short mean residence times are typical of surface horizons (Trumbore, 2000), and make it difficult to distinguish differences in surface SOC turnover. In contrast, mineral soils exhibited generally more pre-bomb $\mathrm{C}$, resulting in longer mean residence times. Mineral soils in the warmest region exhibited shorter mean residence times than those in the cooler regions (modern vs. $310-352$ years). The range in radiocarbon content is consistent with observations in other podzolic forest soils (Kane et al., 2005; van der Voort et al., 2016), and in this study indicates a more rapid turnover of SOC in the warmest region's sites compared to those in the coldest region. The more variable radiocarbon content among sites in the Salmon River region reflects two sites with relatively long mean residence times ( $>300$ year). These longer mean residence times can be explained by the occurrence of glacial till marine deposits containing shale (Table 1). These two sites also exhibited the highest clay content, congruent with the underlying geology of those sites (Van Houton, 1953; Mitchell and Soga, 2005). Extreme windthrow events in this region also likely contribute to the greater variation in mineral soil radiocarbon, $\mathrm{C}$ concentrations and SOC stocks relative to the other regions in this study. Evidence of wood and $\mathrm{O}$ horizon intrusion into mineral soils has been observed in soil pits in this region, congruent with studies of other boreal forest podzols where a history of windthrow events exists (Kramer et al., 2004).

The time that would be required for the mineral SOC in the coldest, highest latitude forests of our study to acquire the radiocarbon signature of the warmest, lowest latitude forests was estimated using a modeling approach. We used a model defining two soil pools with distinct turnover times and in steady state, with a series structure for exchange between the pools (SoilR; Sierra et al., 2014; Supplementary Information). We applied SOC mineralization rates estimated from inverse modeling of radiocarbon content of the warmest region's mineral SOC to SOC stocks in the coldest region. We assumed that the mean proportion of the coarse $(>53 \mu \mathrm{m})$ and fine $(<53 \mu \mathrm{m})$ soil fractions from across all study sites provides an estimate of the proportion of relatively fast and slow turnover soil $\mathrm{C}$ pools. Model simulations indicate that the SOC mineralization rates experienced in the warmest forests would need to be sustained in the coldest region for 10 to 60 years for the coldest region's soils to exhibit the modern radiocarbon signatures observed in the warmest region's soils (Figure 4). The results of this modeling exercise, in conjunction with the estimates of SOC mean residence times, indicate soil $\mathrm{C}$ dynamics across this latitudinal transect are operating on decadal timescales relevant to contemporary climate change. 
Various measures of the extent of decomposition and alteration of soil $\mathrm{OM}$ independently demonstrate relatively minor variability across the transect, despite the higher rates of $\mathrm{C}$ turnover in the lowest latitude forests. The C:N of soil OM decreased with depth at all sites (Figure 5A), and this is indicative of the microbial degradation of C-rich substrates and immobilization of N (Post et al., 1985; Hobara et al., 2013). The

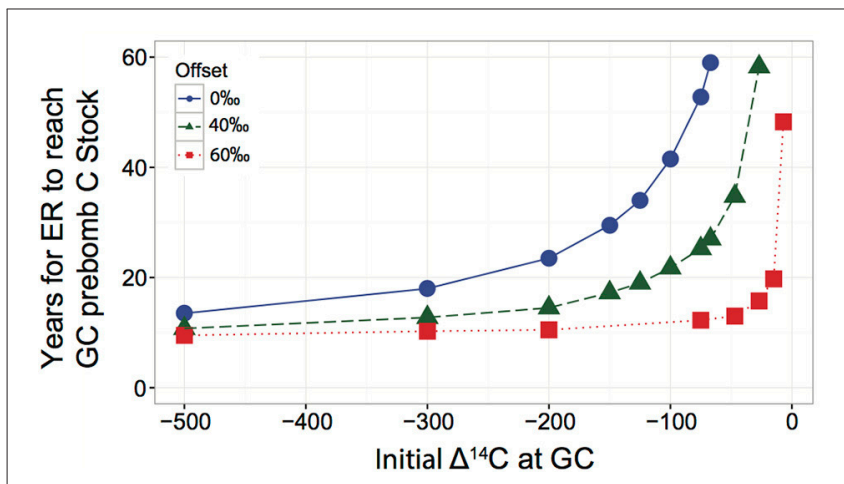

FIGURE 4 | Sensitivity analysis for a range of possible initial $\Delta^{14} \mathrm{C}$ values of pre-bomb $C$ in soil profiles of forests comprising the Newfoundland Labrador Boreal Ecosystem Latitudinal Transect. For each combination of values, the model was run as described in the text and illustrated in Figures S1 and S2; the range of results is reported here. The analysis was performed with the initial pre-bomb $\Delta^{14} \mathrm{C}$ equal in the Eagle River (ER) and Grand Codroy (GC) forest soils (no offset; dashed line with circles) and with ER 40 and $60 \%$ depleted in ${ }^{14} \mathrm{C}$ compared to GC, equivalent to the observed offset between the two regions (offset $=40$ and 60\%; solid line with squares and dashed line with diamonds, respectively). The model scenario in which the initial pre-bomb $\Delta{ }^{14} \mathrm{C}=-67 \%$ at ER forms the upper bound of the sensitivity analysis because more in ${ }^{14} \mathrm{C}$ enriched initial values cannot simulate the formation of SOC with $\Delta^{14} \mathrm{C}=-30 \%$ using the measured fluxes. $\delta^{13} \mathrm{C}$ of soil OM increased with depth (Figure 5B) indicating an increasing extent of degradation (Nadelhoffer and Fry, 1988). Similarly, the amino acid degradation index indicated increasing alteration of soil OM with depth (Figure 5C). Increases in alkyl to $\mathrm{O}$-alkyl ratios with depth were indicative of the preferential decomposition of carbohydrates (Figure 5D) and are consistent with the other diagenetic indicators. Minor latitudinal changes were observed in the C:N and alkyl to O-alkyl ratios of the organic horizons, and this appears to be due to differences in the composition of litter inputs (Kohl et al., Personal Communication; Philben et al., 2016).

The similarity among degradation indices of mineral OM across the latitudinal transect were surprising given the significant differences in radiocarbon content across the regions. The modern mineral soil $\mathrm{OM}$ in the warmest region appears to be as decomposed and altered from fresh litterfall as does soil OM with much longer mean residence time ( $\sim 300$ year) in the coolest region. This demonstrates that radiocarbon signatures are not a reliable indicator of the extent of decomposition of soil $\mathrm{OM}$ in these forests. Combined with soil texture and the noncrystalline mineral content discussed above, these observations further suggest that physiochemical properties, such as mineral surface area, porosity, hydrophobicity and charge, all of which can govern the degree to which OM is susceptible to microbial degradation (Paul, 1984; Baldock and Skjemstad, 2000), may be less important in the preservation of soil OM in these forests than climatic factors.

\section{Maintenance of Mesic Boreal Forest Soil C Stocks with Projected Climate Change}

Climate change includes direct effects of increased temperature and precipitation (Stocker et al., 2013) as well as indirect

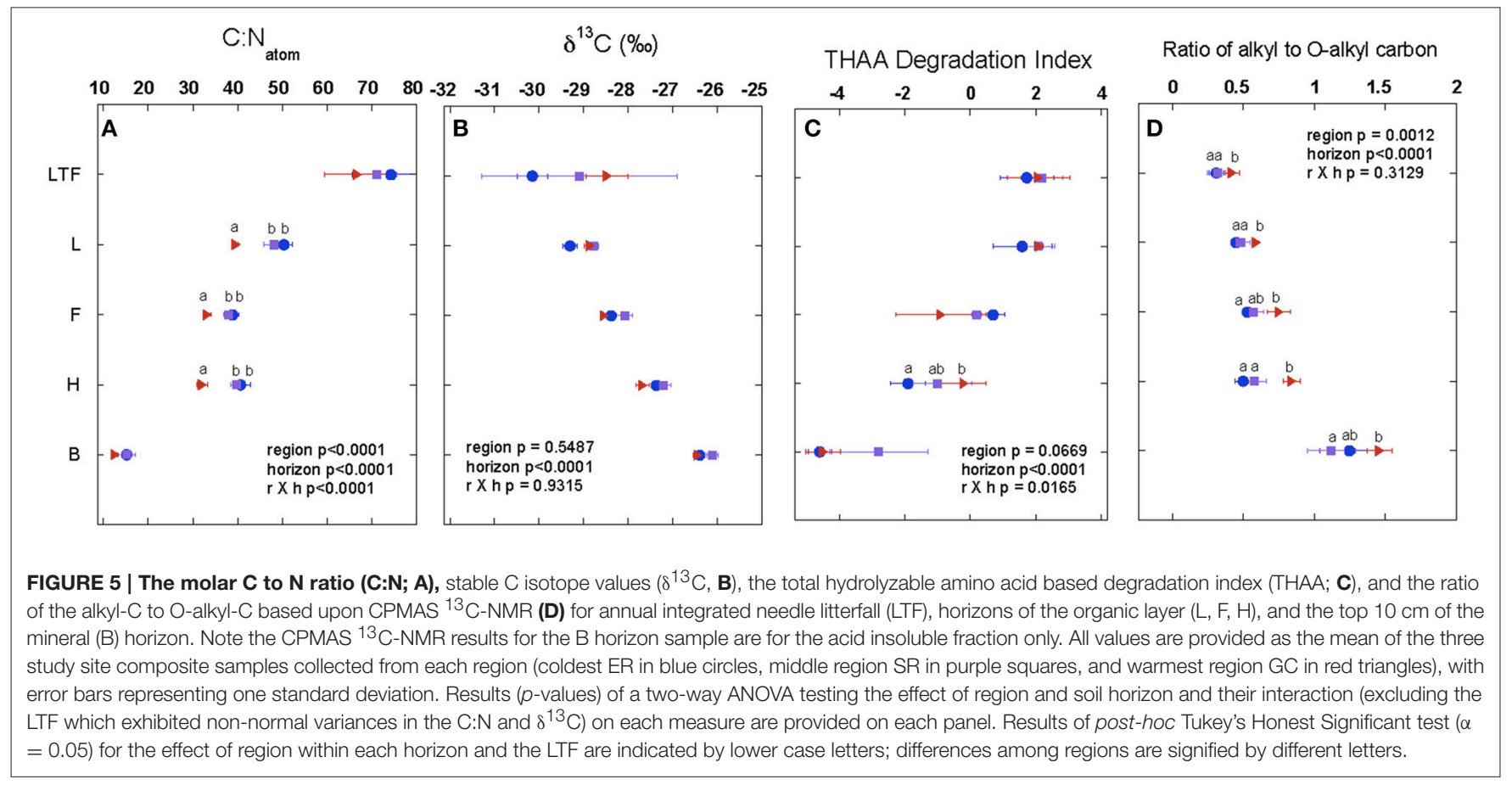


effects such as changes in nutrient cycling, productivity and vegetation composition (Schimel et al., 1994; Asner et al., 1997; Medlyn et al., 2000; Sistla et al., 2014). Integration of these direct and indirect effects and the net responses of soil C, though greatly informed via experimentation (Shaver et al., 1992; Stromgren and Linder, 2002), can be more holistically achieved through the observations of ecosystems that have experienced different climates. The short temporal nature of most ecosystem C flux measures, typically made over years, and the difficulty in obtaining measures of all inputs and losses of soil $\mathrm{C}$ present challenges for tracking soil $\mathrm{C}$ responses to climate change. We gained novel insights of the impacts of anthropogenic climate change in the coming century by combining measurable ecosystem $\mathrm{C}$ fluxes with biogeochemical indicators of SOM transformations. In doing so we obtained an independent and integrative measure of soil $\mathrm{C}$ responses to climate change.

This study provides independent lines of evidence indicating some terrestrial ecosystems, including those projected to experience rapid climate change (Stocker et al., 2013), may not experience net SOC losses to the atmosphere with climate warming this century. In these boreal forests, direct, ecosystemscale observations of accelerated soil $\mathrm{C}$ turnover resulted from enhanced forest productivity, soil respiration, and DOC losses with decreasing latitude. In contrast to global- or continentalscale patterns of SOC occurring across distinct biomes (Jobbágy and Jackson, 2000; Frank et al., 2012), it appears that SOC stocks within mesic boreal forests can be maintained in spite of enhanced SOC losses under climatic conditions projected in the coming decades. This observation is similar to that observed in wet montane tropical forests (Giardina et al., 2014), but the mechanisms responsible for the maintenance of SOC stocks appears to differ between these biomes. In tropical forests, increased soil respiration with warming appears largely supported by root inputs with no evidence for change in turnover of the broader SOC pool (Giardina et al., 2014). In these mesic boreal forests, warming-induced increases in respiration and DOC losses appear supported by enhancement of multiple SOC inputs. If these results prove robust in the coming decades, SOC stocks may not generate a positive feedback to a warming climate, assuming increases in forest productivity and associated inputs to soils are maintained.

\section{REFERENCES}

Amundson, R. (2001). The carbon budget in soils. Annu. Rev. Earth Planet. Sci. 29, 535-562. doi: 10.1146/annurev.earth.29.1.535

Arora, V. K., Boer, G. J., Friedlingstein, P., Eby, M., Jones, C. D., Christian, J. R., et al. (2013). Carbon-concentration and carbon-climate feedbacks in CMIP5 Earth system models. J. Clim. 26, 5289-5314. doi: 10.1175/JCLI-D-12-00494.1

Asner, G. P., Seastedt, T. R., and Townsend, A. R. (1997). The decoupling of terrestrial carbon and nitrogen cycles. Bioscience 47, 226-234. doi: $10.2307 / 1313076$

Bahn, M., Rodeghiero, M., Anderson-Dunn, M., Dore, S., Gimeno, C., Drösler, M., et al. (2008). Soil respiration in European Grasslands in relation to climate and assimilate supply. Ecosystems 11, 1352-1367. doi: 10.1007/s10021-008-9198-0

\section{AUTHOR CONTRIBUTIONS}

All authors contributed to the general conception of the study. $\mathrm{SB}, \mathrm{KE}, \mathrm{JL}$, and SZ designed the sampling. RB, SB, KE, JL, $\mathrm{MP}$, and SZ contributed to field installations and sampling. XZ conducted the field measurements, data analyses, and modeling for the soil $\mathrm{CO}_{2}$ fluxes. $\mathrm{KE}$ conducted the measurements and data analyses for the litterfall and DOC fluxes. JL contributed to soil preparations and conducted the data analyses for elemental and stable isotopic soil analyses. MP conducted the modeling of the soil radiocarbon content, the measurements, data and statistical analyses of the soil amino acids. SZ conducted the data analyses for the radiocarbon and NMR data as well as all other statistical analyses. SZ wrote the manuscript with significant assistance from $\mathrm{SB}$ and $\mathrm{RB}$ and input from all co-authors.

\section{FUNDING}

This research was funded by the NSERC Discovery and Strategic Project (\#397494-10) Grants programs, Centre for Forest Science and Innovation of the Newfoundland and Labrador Agrifoods Agency, Canada Research Chairs Programme, and the Canadian Forest Service of Natural Resources Canada.

\section{ACKNOWLEDGMENTS}

We thank Keri Bowering, Gord Butt, Julia Ferguson, Jamie Warren, Rachelle Dove, Darrell Harris, Danny Pink, Alison Pye, Amanda Baker, Celine Schneider, Andrea Skinner, Thalia Soucy-Giguere, and Catie Young for their laboratory and/or field assistance. Andre Arsenault, Patricia Baines, Robert LeBlanc, and Candice Power generously provided the mean tree age data used in Figure 3. The Biogeochemistry of Boreal Ecosystems Research Group (BBERG) provided feedback on concepts presented. We also thank Jennifer Armstrong for assistance with the generation of Figure 2.

\section{SUPPLEMENTARY MATERIAL}

The Supplementary Material for this article can be found online at: http://journal.frontiersin.org/article/10.3389/feart. 2017.00002/full\#supplementary-material

Baldock, J., and Skjemstad, J. O. (2000). Role of the soil matrix and minerals in protecting natural organic materials against biological attack. Org. Geochem. 31, 697-710. doi: 10.1016/S0146-6380(00)00049-8

Beaudoin, A., Bernier, P. Y., Guindon, L., Villemaire, P., Guo, X. J., Stinson, G., et al. (2014). Mapping attributes of Canada's forests at moderate resolution through kNN and MODIS imagery. Can. J. For. Res. 44, 521-532. doi: 10.1139/cjfr-2013-0401

Bond-Lamberty, B., and Thomson, A. (2010). Temperature-associated increases in the global soil respiration record. Nature 464, 579-582. doi: 10.1038 /nature 08930

Buchmann, N. (2000). Biotic and abiotic factors controlling soil respiration rates in Picea abies stands. Soil Biol. Biochem. 32, 1625-1635. doi: 10.1016/S0038-0717(00)00077-8 
Charney, N. D., Babst, F., Poulter, B., Record, S., Trouet, V. M., Frank, D., et al. (2016). Observed forest sensitivity to climate implies large changes in 21st century North American forest growth. Ecol. Lett. doi: 10.1111/ele.12650

Courchesne, F., and Turmel, M. C. (2007). "Extractable Al, Fe, Mn, and Si," in Soil Sampling and Methods of Analysis, 2nd Edn, eds M. R. Carter and E. G. Gregorich (Boca Raton, FL: Soil Sample and Methods of Analysis, 2nd eds), 307.

Dauwe, B., Middelburg, J. J., Herman, P. M. J., and Heip, C. H. R. (1999). Linking diagenetic alteration of amino acids and bulk organic matter reactivity. Limnol. Oceangr. 44, 1809-1814. doi: 10.4319/lo.1999.44.7.1809

De Deyn, G. B., Cornelissen, J. H., and Bardgett, R. D. (2008). Plant functional traits and soil carbon sequestration in contrasting biomes. Ecol. Lett. 11, 516-531. doi: 10.1111/j.1461-0248.2008.01164.x

Doetterl, S., Stevens, A., Six, J., Merckx, R., Van Oost, K., Pinto, M. C., et al. (2015). Soil carbon storage controlled by interactions between geochemistry and climate. Nat. Geosci. doi: 10.1038/ngeo2516

D’Orangeville, L., Duchesne, L., Houle, D., Kneeshaw, D., Côté, B., and Pederson, N. (2016). Northeastern North America as a potential refugium for boreal forests in a warming climate. Science 352, 1452-1455. doi: 10.1126/science.aaf4951

Dunn, A. L., Barford, C. C., and Wofsy, S. C. (2006). A long-term record of carbon exchange in a boreal black spruce forest: means, responses to interannual variability, and decadal trends. Glob. Change Biol. 13, 577-590. doi: 10.1111/j.1365-2486.2006.01221.x

Fissore, C., Giardina, C., and Swanston, C. (2009). Variable temperature sensitivity of soil organic carbon in North American forests. Glob. Change Biol. 15, 2295-2310. doi: 10.1111/j.1365-2486.2009.01903.x

Frank, D. A., Pontes, A. W., and McFarlane, K. J. (2012). Controls on soil organic carbon stocks and turnover among North American ecosystems. Ecosystems 15, 604-615. doi: 10.1007/s10021-012-9534-2

Friedlingstein, P., Meinshausen, M., Arora, V. K., Jones, C. D., Anav, A., Liddicoat, S. K., et al. (2014). Uncertainties in CMIP5 climate projections due to carbon cycle feedbacks. J. Clim. 27, 511-526. doi: 10.1175/JCLI-D-12-00579.1

Giardina, C. P., Litton, C. M., Crow, S. E., and Asner, G. P. (2014). Warmingrelated increases in soil $\mathrm{CO}_{2}$ efflux are explained by increased below-ground carbon flux. Nat. Clim. Change 4, 822-827. doi: 10.1038/nclimate2322

Harris, R. K., Becker, E. D., Cabral De Menezes, S. M., Goodfellow, R., and Granger, P. (2002). NMR nomenclature: nuclear spin properties and conventions for chemical shifts (IUPAC recommendations 2001). Concepts Magn. Reson. 14, 326-346. doi: 10.1002/cmr.10035

Hedges, J. I., and Stern, J. H. (1984). Carbon and nitrogen determinations of carbonate-containing solids. Limnol. Oceangr. 29, 657-663. doi: 10.4319/lo.1984.29.3.0657

Hilli, S., Stark, S., and Derome, J. (2008). Carbon quality and stocks in organic horizons in boreal forest soils. Ecosystems 11, 270-282. doi: 10.1007/s10021-007-9121-0

Hobara, S., Osono, T., Hirose, D., Noro, K., Hirota, M., and Benner, R. (2013). The roles of microorganisms in litter decomposition and soil formation. Biogeochemistry 118, 471-486. doi: 10.1007/s10533-013-9912-7

Hobbie, S. E., and Chapin, F. S. III (2008). The response of tundra plant biomass, aboveground production, nitrogen, and $\mathrm{CO}_{2}$ flux to experimental warming. Ecology 79, 1562-1544. doi: 2.0.CO;2]10.1890/00129658(1998)079[1526:TROTPB]2.0.CO;2

Hopkins, F. M., Torn, M. S., and Trumbore, S. E. (2012). Warming accelerates decomposition of decades-old carbon in forest soils. Proc. Natl. Acad. Sci. U.S.A. 109, E1753-E1761. doi: 10.1073/pnas.1120603109

Jobbágy, E. G., and Jackson, R. B. (2000). The vertical distribution of soil organic carbon and its relation to climate and vegetation. Ecol. Appl. 10, 423-436. doi: 10.1890/1051-0761(2000)010[0423:TVDOSO]2.0.CO;2

Kane, E. S., Valentine, D. W., Schuur, E. A. G., and Dutta, K. (2005). Soil carbon stabilization along climate and stand productivity gradients in black spruce forests of interior Alaska. Can. J. For. Res. 35, 2118-2129. doi: 10.1139/x05-093

Kane, E. S., and Vogel, J. G. (2009). Patterns of total ecosystem carbon storage with changes in soil temperature in boreal black spruce forests. Ecosystems 12, 322-335. doi: 10.1007/s10021-008-9225-1

Kramer, M. G., Sollins, P., and Sletten, R. S. (2004). Soil carbon dynamics across a windthrow disturbance sequence in southeast Alaska. Ecology 85, 2230-2244. doi: $10.1890 / 02-4098$
Laganière, J., Podrebarac, F., Billings, S. A., Edwards, K. A., and Ziegler, S. E. (2015). A warmer climate reduces the bioreactivity of isolated boreal forest soil horizons without increasing the temperature sensitivity of respiratory $\mathrm{CO}_{2}$ loss. Soil Biol. Biochem. 84, 177-188. doi: 10.1016/j.soilbio.2015.02.025

Lavigne, M. B., Boutin, R., Foster, R. J., Goodine, G., Bernier, P. Y., and Robitaille, G. (2003). Soil respiration responses to temperature are controlled more by roots than by decomposition in balsam fir ecosystems. Can. J. For. Res. 33, 1744-1753. doi: 10.1139/x03-090

Masiello, C. A., Chadwick, O. A., Southon, J., Torn, M. S., and Harden, J. W. (2004). Weathering controls on mechanisms of carbon storage in grassland soils. Glob. Biogeochem. Cycles 18, GB4023-GB4031. doi: 10.1029/2004GB002219

Massiot, D., Fayon, F., Capron, M., King, I., Le Calve, S., Alonso, B., et al. (2002). Modelling one- and two-dimensional solid-state NMR spectra. Magn. Reson. Chem. 40, 70-76. doi: 10.1002/mrc.984

Medlyn, B. E., McMurtrie, R. E., Dewar, R. C., and Jeffreys, M. P. (2000). Soil processes dominate the long-term response of forest net primary productivity to increased temperature and atmospheric CO 2 concentration. Can. J. For. Res. 30, 873-888. doi: 10.1139/cjfr-30-6-873

Melillo, J. M., Butler, S., Johnson, J., Mohan, J., Steudler, P., Lux, H., et al. (2011). Soil warming, carbon-nitrogen interactions, and forest carbon budgets. Proc. Natl. Acad. Sci. U.S.A. 108, 9508-9512. doi: 10.1073/pnas.1018189108

Menzel, P., Anupama, K., Basavaiah, N., Das, B. K., Gaye, B., Herrmann, N., et al. (2015). The use of amino acid analyses in (palaeo-) limnological investigations: a comparative study of four Indian lakes in different climate regimes. Geochim. Cosmochim. Acta 160, 25-37. doi: 10.1016/j.gca.2015.03.028

Mitchell, J. K., and Soga, K. (2005). Fundamentals of Soil Behavior. New York, NY: John Wiley and Sons.

Nadelhoffer, K. F., and Fry, B. (1988). Controls on natural N-15 and C-13 abundances in forest soil organic-matter. Soil Sci. Soc. Am. J. 52, 1633-1640. doi: 10.2136/sssaj1988.03615995005200060024x

Natali, S. M., Schuur, E. A. G., and Rubin, R. L. (2012). Increased plant productivity in Alaskan tundra as a result of experimental warming of soil and permafrost. J. Ecol. 100, 488-498. doi: 10.1111/j.1365-2745.2011.01925.x

Norris, C. E., Quideau, S. A., Bhatti, J. S., and Wasylishen, R. E. (2010). Soil carbon stabilization in jack pine stands along the Boreal Forest Transect Case Study. Glob. Change Biol. 17, 480-494. doi: 10.1111/j.1365-2486.2010.02236.x

Oades, J. M. (1989). “An introduction to organic matter in mineral soils," in Minerals in Soil Environments, eds J. B. Dixon and S. B. Weed (Madison, WI: Soil Science Society of America), 89-159.

Olsson, M. T., Erlandsson, M., Lundin, L., and Nilsson, T. (2009). Organic carbon stocks in Swedish Podzol soils in relation to soil hydrology and other site characteristics. Silva Fenn. 43, 209-222. doi: 10.14214/sf.207

Paul, E. A. (1984). Dynamics of organic-matter in soils. Plant Soil 76, 275-285. doi: 10.1007/BF02205586

Peng, C., Ma, Z., Lei, X., Zhu, Q., Chen, H., Wang, W., et al. (2011). A droughtinduced pervasive increase in tree mortality across Canada's boreal forests. Nat. Clim. Change 1, 467-471. doi: 10.1038/nclimate1293

Philben, M., Ziegler, S. E., Edwards, K. A., Kahler, R. III, and Benner, R. (2016). Soil organic nitrogen cycling increases with temperature and precipitation along a boreal forest latitudinal transect. Biogeochemistry 127, 397-410. doi: 10.1007/s10533-016-0187-7

Podrebarac, F. A., Laganière, J., Billings, S. A., Edwards, K. A., and Ziegler, S. E. (2016). Soils isolated during incubation underestimate temperature sensitivity of respiration and its response to climate history. Soil Biol. Biochem. 93, 60-68. doi: 10.1016/j.soilbio.2015.10.012

Post, W. M., Emanuel, W. R., Zinke, P. J., and Stangenberger, A. G. (1982). Soil carbon pools and world life zones. Nature 298, 156-159. doi: 10.1038/298156a0

Post, W. M., Pastor, J., Zinke, P. J., and Stangenberger, A. G. (1985). Global patterns of soil-nitrogen storage. Nature 317, 613-616. doi: 10.1038/317613a0

Preston, C. M., Bhatti, J. S., Flanagan, L. B., and Norris, C. (2006). Stocks, chemistry, and sensitivity to climate change of dead organic matter along the Canadian boreal forest transect case study. Clim. Change 74, 223-251. doi: 10.1007/s10584-006-0466-8

Qian, H., Joseph, R., and Zeng, N. (2010). Enhanced terrestrial carbon uptake in the Northern High Latitudes in the 21st century from the coupled carbon cycle climate model intercomparison project model projections. Glob. Change Biol. 16, 641-656. doi: 10.1111/j.1365-2486.2009.01989.x 
Ruess, R. W., Cleve, K. V., Yarie, J., and Viereck, L. A. (1996). Contributions of fine root production and turnover to the carbon and nitrogen cycling in taiga forests of the Alaskan interior. Can. J. For. Res. 26, 1326-1336. doi: 10.1139/x26-148

Rustad, L., Campbell, J., Marion, G., Norby, R., Mitchell, M., Hartley, A., et al. (2001). A meta-analysis of the response of soil respiration, net nitrogen mineralization, and aboveground plant growth to experimental ecosystem warming. Oecologia 126, 543-562. doi: 10.1007/s004420000544

Schimel, D. S., Braswell, B. H., Holland, E. A., McKeown, R., Ojima, D. S., Painter, T. H., et al. (1994). Climatic, edaphic, and biotic controls over storage and turnover of carbon in soils. Global Biogeochem. Cycles 8, 279-293. doi: 10.1029/94GB00993

Schlesinger, W. H., and Bernhardt, E. S. (2013). Biogeochemistry: An Analysis of Global Change, 3rd Edn. Waltham, MA: Academic Press.

Schmidt, M. W. I., Knicker, H., Hatcher, P. G., and Kögel-Knabner, I. (1997). Improvement of $13 \mathrm{C}$ and $15 \mathrm{~N}$ CPMAS NMR spectra of bulk soils, particle size fractions and organic material by treatment with $10 \%$ hydrofluoric acid. Eur. J. Soil Sci. 48, 319-328. doi: 10.1111/j.1365-2389.1997. tb00552.x

Shaver, G. R., Billings, W. D., Chapin, F. S. III, Giblin, A. E., Nadelhoffer, K. J., Oechel, W. C., et al. (1992). Global change and the carbon balance of arctic ecosystems. BioScience 42, 433-441. doi: 10.2307/1311862

Sierra, C., Müller, M. M., and Trumbore, S. E. (2014). Modeling Radiocarbon Dynamics in Soils: Soil R Version 1.1. GMD 7, 1919-1931.

Sistla, S. A., Moore, J. C., Simpson, R. T., Gough, L., Shaver, G. R., and Schimel, J. P. (2014). Long-term warming restructures Arctic tundra without changing net soil carbon storage. Nature 497, 615-618. doi: 10.1038/nature12129

Sjogersten, S., Turner, B. L., and Mahieu, N. (2003). Soil organic matter biochemistry and potential susceptibility to climatic change across the foresttundra ecotone in the Fennoscandian mountains. Glob. Change Biol. 9, 759-772. doi: 10.1046/j.1365-2486.2003.00598.x

Soukup, D. A., Buck, B. J., and Harris, W. (2008). "Preparing samples for mineralogical analyses," in Methods of Soil Analyses Mineralogical Methods Part, eds A. L. Ulery and L. R. Drees (Madison, WI: Soil Science Society of America), 13-32.

Stocker, T. F., Qin, D., Plattner, G. K., Tignor, M. M. B., Allen, S. K., Boschung, J., et al. (2013). Change 2013: The Physical Science Basis: Working Group I Contribution to the Fifth Assessment Report of the Intergovernmental Panel on Climate Change. Intergovernment Panel on Climate Change, Universitat Bern, Bern.

Stromgren, M., and Linder, S. (2002). Effects of nutrition and soil warming on stemwood production in a boreal Norway spruce stand. Glob. Change Biol. 8, 1195-1204. doi: 10.1046/j.1365-2486.2002.00546.x
Todd-Brown, K. E. O., Randerson, J. T., Post, W. M., Hoffman, F. M., Tarnocai, C., Schuur, E. A. G., et al. (2013). Causes of variation in soil carbon simulations from CMIP5 Earth system models and comparison with observations. Biogeosciences 10, 1717-1736. doi: 10.5194/bg-10-1717-2013

Torn, M. S., Trumbore, S. E., Chadwick, O. A., Vitousek, P. M., and Hendricks, D. M. (1997). Mineral control of soil organic carbon storage and turnover. Nature 389, 170-173. doi: 10.1038/38260

Trumbore, S. (2000). Age of soil organic matter and soil respiration: radiocarbon constraints on belowground C dynamics. Ecol. Appl. 10, 399-411. doi: 10.1890/ 1051-0761(2000)010[0399:AOSOMA]2.0.CO;2

Trumbore, S., and Harden, J. (1997). Accumulation and turnover of carbon in organic and mineral soils of the BOREAS northern study area. J. Geophys. Res. Atmos 102, 28817-28830. doi: 10.1029/97JD02231

van der Voort, T. S., Hagedorn, F., McIntyre, C., Zell, C., Walthert, L., Schleppi, P., et al. (2016). Variability in ${ }^{14} \mathrm{C}$ contents of soil organic matter at the plot and regional scale across climatic and geologic gradients. Biogeosci. Discuss. 13, 3427-3439. doi: 10.5194/bg-2015-649

Van Houton, F. B. (1953). Clay minerals in sedimentary rocks and derived soils. Am. J. Sci. 251, 61-82. doi: 10.2475/ajs.251.1.61

Vogel, J. S., Nelson, D. E., and Southon, J. R. (1987). (super 14) C background levels in an accelerator mass spectrometry system. Radiocarbon 29, 323-333. doi: $10.1017 /$ S0033822200043733

Vogel, J. S., Southon, J. R., Nelson, D. E., and Brown, T. A. (1984). Performance of catalytically condensed carbon for use in accelerator mass spectrometry. $\mathrm{Nucl}$. Instrum. Methods Phys. Res. Sect. B. Beam Interact. Materials Atoms 5, 289-293. doi: 10.1016/0168-583X(84)90529-9

Zimmermann, M., Meir, P., Bird, M. I., Malhi, Y., and Ccahuana, A. J. Q. (2009). Climate dependence of heterotrophic soil respiration from a soil-translocation experiment along a $3000 \mathrm{~m}$ tropical forest altitudinal gradient. Eur. J. Soil Sci. 60, 895-906. doi: 10.1111/j.1365-2389.2009.01175.x

Conflict of Interest Statement: The authors declare that the research was conducted in the absence of any commercial or financial relationships that could be construed as a potential conflict of interest.

Copyright (C) 2017 Ziegler, Benner, Billings, Edwards, Philben, Zhu and Laganière. This is an open-access article distributed under the terms of the Creative Commons Attribution License (CC BY). The use, distribution or reproduction in other forums is permitted, provided the original author(s) or licensor are credited and that the original publication in this journal is cited, in accordance with accepted academic practice. No use, distribution or reproduction is permitted which does not comply with these terms. 